\title{
Hubungan Tingkat Pengetahuan Tentang Anemia Dengan Kepatuhan Ibu Hamil Meminum Tablet Zat Besi Di Puskesmas Sengkol
}

\author{
Dian Soekmawaty Riezqy Ariendha Sri Handayani, Yopi Suryatim Pratiwi, Hardaniyati \\ Email: Diansoekmawaty.ra@ stikesyarsimataram.ac.id
}

Prodi Kebidanan Jenjang D.3 STIKes Yarsi Mataram

\begin{abstract}
ABSTRAK
Tujuan dari penelitian ini adalah untuk mengetahui mencari hubungan tingkat pengetahuan ibu hamil tentang anemia dengan kepatuhan ibu hamil mengkonsumsi tablet zat besi di Puskesmas Sengkol Kabupaten Lombok Tengah. Metode penelitian ini Penelitian ini merupakan penelitian observasional pendekatan cross sectional, dilakukan pada bulan Maret 2019 populasi ibu hamil anemia, sampel diambil secara simpel random sampling sebanyak 30 responden, Analisis data menggunakan analisis univariat, analisis bivariat menggunakan chi square. Hasil penelitian ini didapatkan Responden yang mempunyai tingkat pengetahuan ibu terbanyak adalah yang tahu tentang anemia yaitu 27 responden $(90 \%)$, dan yang tidak tahu tentang anemia adalah sebanyak 3 responden $(10 \%)$. Responden yang memiliki kepatuhan meminum tablet zat besi yaitu 23 responden $(76,7 \%)$, dan yang tidak patuh meminum zat besi yaitu 7 responden $(23,3 \%)$. hasil analisa menggunakan chi-square didapatkan Adanya hubungan bermakna antara tingkat pengetahuan ibu hamil dalam mengkonsumsi tablet zat besi $p$-value $<\alpha(0,05)$. Dimana nilai $\mathrm{p}=0,009$ dikarenakan $\mathrm{p}$-value $<\alpha(0,05)$. Kesimpulan Terdapat hubungan bermakna antara hubungan tingkat pengetahuan ibu hamil tentang anemia dengan kepatuhan ibu hamil mengkonsumsi tablet zat besi di Puskesmas Sengkol
\end{abstract}

Kata Kunci: Anemia, Pengetahun, Kepatuhan meminum tablet zat besi

\begin{abstract}
The purpose of this study was to research pregnant woman research on anemia with pregnant women using substance tablets at the Sengkol Health Center, Central Lombok District. This research method is an observational study using a cross sectional study, using a questionnaire conducted in March-April 2019 as pregnant women with anemia, samples taken with simple random sampling from 30 respondents, data analysis using univariate analysis, bivariate analysis using chi square. The results of this study were obtained by respondents who had the highest knowledge from mothers who knew about anemia, 27 respondents $(90 \%)$, and those who did not know about anemia were 3 respondents (10\%). Respondents who used tablets using substances were 23 respondents $(76.7 \%)$, and those who used iron were 7 respondents $(23.3 \%)$. the results of the analysis using chi-square obtained a relationship associated with the level of knowledge of pregnant women in consuming $\mathrm{p}$-value tablets $<\alpha(0.05)$. Where the value of $\mathrm{p}=$ 0.009 because the value of $p<\alpha(0.05)$. The conclusion is the relationship between the level of knowledge of pregnant women about anemia with the contribution of pregnant substance tablets at the Sengkol Health Center
\end{abstract}

Keywords: Anemia, Knowledge, Compliance taking iron tablets

\section{A. LATAR BELAKANG}

Anemia adalah salah satu masalah gizi yang secara global mempengaruhi wanita hamil sekitar 32,4 juta $(38,2 \%)$ [1]. Masalah anemia merupakan masalah kesehatan masyarakat yang cukup parah dimana Asia Tenggara teradapat (48,7\%) dan Afrika (46,3\%) masalah anemia[1]. Efek Anemia selama kehamilan diantaranya dapat menyebabkan infeksi nifas, plasenta previa, bayi berat lahir rendah, kehairan 
prematur, dan kematian prenatal [2][4]. Angka Kematian Ibu di seluruh dunia berjumlah 510.000 kematian pertahun disebabkan oleh persalinan dan awal post partum, sekitar $20 \%$ kematian ibu disebabkan oleh anemia terutama di negara berkembang.[4]

Wanita Hamil di negara berkembang, memulai kehamilannya dengan kondisi tubuh yang cadangan zat besi dan vitamin lainnya sudah terkuras, hal ini dikarenakan karena asupan gizi yang kurang, infeksi yang berulang, kehilangan darah saat menstrusasi dan persalinan yang banyak. Hali ini terkait juga dengan faktor pengetahuan, gaya hidup, kodisi sosial ekonomi, gaya hidup, dan faktor budaya tertentu [2][3].

Kehamilan secara signifikan meningkatkan kebutuhan zat besi; hal ini merupakan perubahan fisiologis dramatis pada ibu dan Meningkatnya kebutuhan janin yang berkembang mengarah ke perubahan hematologis ibu, yang meningkatkan massa merah sel darah dan, pada trimester ketiga, kebutuhan volume darah sangat dibutuhkan [5][8]. Suplemen universal prenatal dengan asam besi-folat tablet efektif untuk mencegah anemia dan kekurangan zat besi.[9]

Anemia pada ibu hamil dihubungkan dengan meningkatnya kelahiran prematur, kematian ibu dan anak dan penyakit infeksi. Anemia defisiensi besi pada ibu dapat mempengaruhi pertumbuhan dan berkembangan janin/bayi saat kehamilan maupun setelahnya[10]. Berdasarkan hasil Riset Kesehatan Dasar (Riskesdas) tahun 2013, prevalensi anemia pada ibu hamil di Indonesia $37,1 \%$, dan naik menjadi 48,9\% ditahun 2018 [11][12].

Dengan demikian keadaan ini mengindikasi bahwa anemia gizi besi masih menjadi masalah kesehatan masyarakat. Menurut WHO 40\% kematian ibu dinegara berkembang berkaitan dengan anemia pada kehamilan dan kebanyakan anemia pada kehamilan disebabkan oleh defisiensi besi. Dari hasil penelitian sebelumnya, persalinan pada wanita hamil yang menderita anemia defisiensi besi didapatkan 12-28\% kematian janin, 30\% kematian perinatal dan 7$10 \%$ angka kematian neonatal.[8]
Cakupan pemberian TTD pada ibu hamil di Indonesia tahun 2017 adalah 80,81\%. Angka ini belum mencapai target Renstra tahun 2017 yaitu 90\%. Provinsi dengan cakupan tertinggi pemberian TTD pada ibu hamil adalah DKI Jakarta (96,38\%), sedangkan provinsi dengan cakupan terendah adalah Kalimantan Timur $(27,91 \%)$. Ada tujuh provinsi yang sudah melampaui target Renstra tahun 2017. Sedangkan cakupan pemberian TTD pada ibu hamil di NTB mencapai 58,6\%.[10]

Berdasarkan profil kesehatan Provinsi Nusa Tenggara Barat (NTB) prevalensi anemia di Provinsi NTB sebesar 86,6\%, angka tersebut menunjukan bahwa anemia pada ibu hamil beresiko 15,3 kali menyebabkan terjadinya kematian ibu akibat komplikasi kehamilan, persalinan dan nifas dibandingkan ibu yang tidak menderita anemia. Pemerintah Kabupaten Lombok Tengah telah memberikan pemeriksaan ibu hamil secara gratis dan pemberian tablet fe, namun kasus anemia masih sangat tinggi ( Dikes NTB, 2012)[13].

Penelitian Erwin, R. R., Machmud, R. \& Utama, B. I (2013) menjelaskan bahwa rendahnya ibu hamil mengkonsumsi tablet di Puskesmas Seberang Padang dapat disebabkan karena masih banyak ibu hamil yang memiliki pengetahuan kurang mengenai zat besi [14]. Akibatnya, kesadaran ibu hamil untuk mengkonsumsi tablet tambah darah juga masih rendah. Pengetahuan mengenai kebutuhan zat besi, manfaat pada zat besi, sumber makanan mengandung zat besi, akibat yang ditimbulkan apabila kekurangan zat besi, dan informasi lainnya dapat diperoleh ibu melalui penyuluhan yang diberikan petugas kesehatan dalam kunjungan ANC.

Anemia defisiensi besi dapat menyebabkan Bayi Berat Lahir Rendah, penurunan resistensi terhadap infeksi, perkembangan kognitif yang buruk dan kapasitas kerja yang berkurang [15]. Sementara banyak program perawatan antenatal yang mendistribusikan suplemen zat besi untuk wanita hamil, namun efektivitas intervensi ini dalam mengurangi ibu anemia tidak memadai. 
Kepatuhan terhadap pengobatan besi (mis. kegagalan minum pil) adalah kemungkinan alasan untuk ketidakefektifan tersebut program [16]. Untuk mencegah anemia setiap ibu hamil diharapkan mendapatkan tablet tambah darah (TTD) minimal 90 tablet selama kehamilan[17].

Tetapi efektivitas dan keberhasilan intervensi tersebut tergantung pada kepatuhan terhadap konsumsi tablet FE[18]. Kepatuhan menggambarkan derajatnya di mana pasien dengan benar mengikuti saran medis. Banyak ahli percaya bahwa salah satu alasan utama bahwa program suplementasi besi nasional memiliki kegagalan terhadap kepatuhan Tidak ada batas yang jelas tentang kepatuhan, namun bila tidak mengonsumsi 2 dosis atau lebih dapat dikatakan sebagai ketidak patuhan [19][20].

Pada saat ini di Indonesia, supelementasi besi dikerjakan secara rutin pada kelompok ibu hamil di Pusat Kesehatan Masyarakat (Puskesmas) dan Pos pelayanan Terpadu (posyandu) yaitu menggunakan tablet yang berisi besi dan asam folat. Setiap tablet mengandung 60 $\mathrm{mg}$ besi dan $0.25 \mathrm{mg}$ asam folat. Cakupan pemberian tablet Fe di Puskesmas Sengkol pada tahun 2017 sudah cukup baik yaitu cakupan pemberian tablet $\mathrm{Fe} 1100 \%$ akan tetapi prevalensi anemia masih relatife tinggi [13].

Dari hasil studi pendahuluan di Dinas Kesehatan Kabupaten Lombok Tengah tahun 2017 jumlah anemia pada ibu hamil bulan desember 2017 di wilayah kerja puskesmas sengkol sebesar 251 ibu hamil, dari angka tersebut merupakan angka tertinggi dari 25 puskesmas yang berada di Kabupaten Lombok Tengah. Mengingat berbagai dampak buruk yang timbul akibat anemia pada ibu hamil serta prevalensi ibu di provinsi Nusa Tenggar Barat (NTB) cukup tinggi, maka peneliti tertarik untuk melakukan penelitian tentang faktor-faktor yang mempengaruhi anemia pada ibu hamil dipuskesmas sengkol [10][21].

Berdasarkan uraian tersebut tujuan dari penelitian ini untuk mengetahui hubungan tingkat pengetahuan tentang anemia dengan kepatuhan ibu hamil meminum tablet zat besi di puskesmas sengkol,Lombok Tengah.

\section{B. METODE PENELITIAN}

\section{Desain Penelitian}

Penelitian ini merupakan penelitian kuantitatif menggunakan data primer dilakukan menggunakan pendekatan Cross sectional dengan desain analitik korelasional yaitu merupakan penelitian yang mengkaji hubungan antara variabel dengan cara mencari menjelaskan hubungan, memperkirakan dan menguji teori yang ada [22].

\section{Populasi dan Sampel Penelitian}

Popuasi dalam penelitian ini adalah sebagian ibu hamil anemia yang memeriksakan kandungannya ke puskesmas Sengkol populasi sebanyak 50 orang, yang memenuhi kriteria sampel. Kriteria inklusi dalam penelitian ini adalah ibu hamil trimester II dan Trimester III dan bersedia menjadi responden. Kriteria Eksklusi dalam penelitian ini adalah, responden tidak ditemui pada saat dilakukan kunjungan 3 kali, ibu yang sudah melahirkan, jika alamat responden dibuku register tidak lengkap. Tehnik pengambilan sampel yaitu sampel random sampling sebanyak 30 sampel.

\section{Variabel Penelitian}

Variabel bebas dalam penelitian ini adalah Pengetahuan Tentang anemia ukur menggunakan kuesioner yang sudah di berikan dan variabel terikatnya adalah Kepatuhan ibu mengkonsumsi zat besidilihat dari hasil hasil kuesioner.

\section{Waktu dan Lokasi Penelitian}

Penelitian ini dilakukan di Puskesmas sengkol pada bulan Maret 2019 dipuskesmas Sengkol.

\section{Metode Pengumpulan dan Pengolahan data}

Alat pengumpulan data yang digunakan dalam penelitian ini adalah data primer berupa kuesioner dan pemeriksaan kadar $\mathrm{Hb}$, data sekunder berupa pengambilan data dari buku register PWS KIA. Dalam proses pengumpulan data didalam penelitian ini, peneliti turun 
langsung untuk mengadakan pendekatan kepada untuk menyerahkan kuesioner kepada ibu hamil dengan status anemia dan penjelasan tentang isi kuesioner yang akan digunakan.

Data kemudian diolah menggunakan bantuan komputerisasi SPSS, meliputi analisis diskriptif(analisis Univariat) dan Bivariat. Uji statistik yang digunakan dalam penelitian ini disesuaikan dengan skala datanya, yaitu interval, nominal, ordinal dan rasio maka dilakukan uji statistik non parametric dengan uji korelasi chi square. Dengan menggunakan batas kemaknaan $\alpha<0,05$. Dimana bila nilai $\mathrm{P}$ value $(<0,05)$ dinayatakan ada hubungan yang bermakna dan $\mathrm{P}$ value $(>0,05)$ dinayatakan tidak ada hubungan yang bermakna (Dahlan,Sopiyudin, 2014)[23].

\section{Etika Penelitian}

Penelitian ini berupaya memegang teguh sikap ilmiah dan etika dalam penelitian serta berusaha meminimalkan kerugian yang timbul dan memaksimalkan penelitian

\section{HASIL DAN PEMBAHASAN}

Hasil Penelitian ini berjudul hubungan Tingkat Pengetahuan Tentang Anemia Dengan Kepatuhan Ibu Hamil Meminum Tablet Zat Besi Di Puskesmas Sengkol.

\section{Karakteristik Responden}

Tabel I Distribusi Frekuensi responden Berdasarkan Usia Ibu

\begin{tabular}{|l|c|r|}
\hline Usia Ibu & N & $\%$ \\
\hline$<20$ Tahun & 10 & 33,3 \\
\hline $20-30$ tahun & 19 & 63,3 \\
\hline$>30$ tahun & 1 & 3,3 \\
\hline Jumlah & 30 & 100 \\
\hline \multicolumn{2}{|c|}{ Sumber $:$ Data Primer Priode Maret }
\end{tabular}

Tabel 1 diatas menunjukkan bahwa dari 30 responden,yang memiliki umur $<20$ tahun berjumlah 10 responden(33,3\%),umur 20-35 tahun berjumlah 19 responden $(63,3 \%)$ dan umur >35 tahun berjumlah 1 responden (3,3\%)

Tabel 3 Distribusi Frekuensi responden Berdasarkan Pendidikan

\begin{tabular}{|c|c|c|}
\hline Pendidikan & Frekuensi & Presentase(\%) \\
\hline SMP & 19 & 63,3 \\
\hline SMA & 10 & 33,3 \\
\hline
\end{tabular}

\begin{tabular}{|c|c|c|}
\hline PT & 1 & 3,3 \\
\hline Jumlah & 30 & 100 \\
\hline
\end{tabular}

Berdasarkan tabel 2 distribusi frekuensi responden berdasarkan pendidikan, didapatkan ibu hamil yang yang meliliki pendidikan SMP berjumlah 19 responden (63,3\%),memiliki pendidikan SMA berjumlah 10 responden $(33,3 \%)$ dan yang meliliki pendidikan Perguruan Tinggi berjumlah 1 responden $(3,3 \%)$.

Tabel 3 Distribusi Frekuensi responden Berdasarkan Pekerjaan

\begin{tabular}{|c|c|c|}
\hline Pekerjaan & Frekuensi & Presentase (\%) \\
\hline IRT & 29 & 96,7 \\
\hline PNS & 0 & 0 \\
\hline Wiraswasta & 1 & 3,3 \\
\hline Jumlah & 30 & 100 \\
\hline
\end{tabular}

Berdasarkan tabel 3 distribusi frekuensi responden berdasarkan pekerjaan, didapatkan ibu hamil yang yang memiliki pekerjaan IRT berjumlah 29 responden $(96,7 \%)$, memiliki pekerjaan Wiraswasta berjumlah 1 responden $(3,3 \%)$.

\section{Analisis Univariat}

Tabel 4. Distribusi responden berdasarkan tingkat pengetahuan ibu hamil tentang anemia

\begin{tabular}{|c|c|c|}
\hline $\begin{array}{c}\text { Tingkat } \\
\text { Pengetahuan }\end{array}$ & Frekuensi & Presentase(\%) \\
\hline Tahu & 27 & $90 \%$ \\
\hline Tidak Tahu & 3 & $10 \%$ \\
\hline Jumlah & 30 & $100 \%$ \\
\hline
\end{tabular}

Sumber : Data Primer Priode Maret

Tabel 4 diatas menunjukkan bahwa dari 30 responden yang memiliki tingkat pengetahuan ibu yang tahu tentang anemia berjumlah 27 responden (90\%). Dan yang tidak tahu tentang anemia berjumlah 3 responden (10\%). Kepatuhan Mengkonsumsi Tablet besi

Tabel 5 Distribusi responden berdasarkan kepatuhan mengkonsumsi tablet zat besi

\begin{tabular}{l|l|l|} 
Kepatuhan & Frekuensi & Presentase(\%) \\
\hline
\end{tabular}




\begin{tabular}{|c|c|c|}
\hline Patuh & 23 & $76,7 \%$ \\
\hline Tidak patuh & 7 & $23,3 \%$ \\
\hline Jumlah & 30 & $100 \%$ \\
\hline
\end{tabular}

Sumber : Data Primer Periode Maret

Tabel 5 diatas menunjukkan bahwa dari 30 responden yang patuh mengkonsumsi tablet besi berjumlah 23 responden $(76,7 \%)$, dan yang tidak patuh meminum zat besi berjumlah 7 responden $(23,3 \%)$.

\section{Analisis Bivariat}

Tabel 6 Distribusi responden berdasarkan hubungan tingkat pengetahuan ibu hamil tentang anemia dengan Kepatuhan Mengkonsumsi Tablet Zat Besi

\begin{tabular}{|c|c|c|c|c|c|c|c|c|}
\hline \multirow{3}{*}{$\begin{array}{c}\text { Tingkat } \\
\text { Pengetah } \\
\text { uan Ibu } \\
\text { Hamil }\end{array}$} & \multicolumn{4}{|c|}{ Kepatuhan } & \multirow{2}{*}{\multicolumn{2}{|c|}{ Total }} & \multirow{3}{*}{$X^{2}$} & \multirow{3}{*}{$\begin{array}{c}\mathrm{P} \\
\text { Value }\end{array}$} \\
\hline & \multicolumn{2}{|c|}{ Patuh } & \multicolumn{2}{|c|}{$\begin{array}{l}\text { Tidak } \\
\text { Patuh }\end{array}$} & & & & \\
\hline & $\mathrm{N}$ & $\%$ & $\mathrm{~N}$ & $\%$ & $\mathrm{~N}$ & $\%$ & & \\
\hline Tahu & 23 & 85,2 & 4 & 14,8 & 27 & 76,3 & \multirow{3}{*}{$\begin{array}{c}10, \\
952\end{array}$} & \multirow{3}{*}{0,009} \\
\hline $\begin{array}{l}\text { Tidak } \\
\text { Tahu }\end{array}$ & 0 & 0 & 3 & 10,0 & 3 & 23,3 & & \\
\hline Total & 23 & 85,2 & 7 & 14,8 & 30 & 100 & & \\
\hline
\end{tabular}

Sumber data primer peiode Maret

Tabel 6 menunjukkan bahwa dari 30 responden Tabel 4.6 menunjukkan dari 27 responden yang pengetahuannya tahu tentang anemia ada $23(85,19 \%)$ responden yang patuh mengkonsumsi tablet zat besi dan yang tidak patuh ada 4 responden (14,8\%), sedangkan yang pengetahuannya tidak tahu tentang anemia dan tidak patuh mengkonsumsi tablet zat besi ada 3 reponden $(10,00 \%)$.

Dari hasil uji statistic yang menggunakan Chi Square terdapat $\mathrm{Df}=1$ dengan $\alpha=0,05$, menunjukan adanya hubungan yang signifikan dengan nilai $\mathrm{p}=0,009(p<0,05)$, dan diperoleh nilai $X^{2}$ hitung $=10,952>X^{2}$ Tabel $=3,841$ dengan demikian $\mathrm{H} 0$ ditolak dan Ha diterima, berarti ada hubungan antara tingkat pengetahuan ibu hamil tentang anemia dengan kepatuhan mengkonsumsi tablet zat besi di Puskesmas Sengkol priode Mare 2019. Makin baik pengetahuan ibu ibu tentang anemia maka semakin patuh ibu dalam mengkonsumsi tablet zat besi.

\section{Tingkat Pengetahuan Ibu Hamil Tentang}

\section{Anemia}

Hasil penelitian Tabel 4 menunjukkan bahwa 30 responden yang memiliki tingkat pengetahuan ibu yang tahu tentang anemia yaitu 27 responden (90\%). Dan yang tidak tahu tentang anemia adalah sebanyak 3 responden $(10 \%)$.

Notoadmojo, (2014) mengatakan pengetahuan merupakan hasil penginderaan manusia atau hasil tahu seseorang terhadap objek melalui indra yang dimilikinya (mata, hidung, telinga, dan sebagainya). Pengetahuan yang diperoleh seseorang dapat dipengaruhi oleh beberapa faktor yaitu usia, pendidikan, pekerjaan, kultur, pengalaman, informasi, dan lingkungan[24].

Banyak penelitian menunjukkan bahwa faktor-faktor seperti pendidikan, usia pada perkawinan, status sosial ekonomi, pengetahuan buruk, jarak kelahiranyang dekat dan riwayat anemia sebelum kehamilan adalah penentu signifikan anemia.[25]

Studi Lain Menjelaskan tentang pengaruh pengetahuan dan sikap tentang Anemia di India Selatan menemukan bahwa, pada wanita di daerah pedesaan menyebabkan kurangnya pengetahuan tentang asupan zat besi yang di konsumsi dan kurangnya konseling oleh petugas kesehatan adalah penyebab signifikan terjadinya anemia [26].

Dalam penelitian ini pengetahuan lebih tinggi pada ibu hamil yang tahu $(76,7 \% \%)$ dibandingkan yang tidak tahu $(23,3 \% \%)$.

\section{Kepatuhan Ibu Hamil Mengkonsumsi Tablet Zat Besi}

Hasil penelitian Tabel 5 menunjukkan bahwa 30 responden yang patuh mengkonsumsi tablet besi adalah 23 responden $(76,7 \%)$, dan yang tidak patuh meminum zat besi yaitu 7 responden $(23,3 \%)$.

Kepatuhan dengan suplementasi zat besi memainkan peran utama dalam pencegahan dan pengobatan anemia defisiensi besi khususnya di antara wanita hamil yang kebutuhan zat besinya mulai dari trimester kedua dan berlanjut hingga trimester ketiga. Jadi ini studi berusaha untuk 
menyelidiki faktor yang terkait dengan kepatuhan suplemen zat besi folat prenatal [27]. Hasilnya mengungkapkan itu $90 \%$ wanita patuh lebih banyak dibandingkan ibu hamil yang tidak patuh (10\%).

\section{Diskusi Hasil Analisis Bivariat}

Tabel 6 menunjukkan 27 responden yang pengetahuannya tahu tentang anemia ada 23 responden yang patuh mengkonsumsi tablet besi $(85,2 \%)$ dan yang tidak patuh ada 4 responden $(14,8 \%)$ sedangkan yang pengetahuannya tidak tahu tentang anemia dan tidak patuh mengkonsumsi tablet Zat besi ada 3 responden $(10,00 \%)$.

Hal ini menandakan bahwa semakin baik pengetahuan ibu tentang anemia maka semakin patuh ibu dalam mengkonsumsi tablet zat besi dalam menjaga kesehatan dalam kehamilan.

Dari hasil uji statistic yang menggunakan Chi Square terdapat $\mathrm{Df}=1$ dengan $\alpha=0,05$, menunjukan adanya hubungan yang signifikan dengan nilai $\mathrm{p}=0,009(\mathrm{p}<0,05)$, dan diperoleh nilai hitung $=10,952>$ Tabel $=3,841$ dengan demikian H0 ditolak dan Ha diterima,berarti ada hubungan antara tingkat pengetahuan ibu hamil tentang anemia dengan kepatuhan mengkonsumsi tablet zat besi di Puskesmas Sengkol.

Menurut Nivedita K, Shanthini (2016) [28] pengetahuan merupakan domain yang sangat penting untuk terbentuknya tindakan seseorang. Berdasarkan pengalaman dan penelitian ternyata tindakan yang disadari oleh pengetahuan akan lebih teratur daripada tindakan yang tidak disadari oleh pengetahuan. Pengetahuan tentang gizi dapat menghindarkan seseorang dari konsumsi pangan yang salah. Dengan tingkat pengetahuan yang baik, ibu hamil dapat mengetahui bahan pangan yang dapat membahayakan kehamilannya serta dapat memilih hal-hal yang dapat menunjang kualitas kehamilannya terutama yang terkait dalam mengkonsumsi obat-obat untuk kehamilan, termasuk dengan obat tablet besi yang dibagikan oleh petugas puskesmas yang ditujukan untuk kesehatan selama selama kehamilan. [29]
Mengonsumsi suplemen zat besi dapat mengurangi $70 \%$ risik anemia ibu dan defisiensi besi 57\% [30]. Menurut Saxena (2014), penggunaan zat besi suplemen membantu meningkatkan status zat besi ibu selama kehamilan dan selama postpartum bahkan pada wanita yang memasuki kehamilan dengan cadangan besi yang baik [31].

Tingginya tingkat pengetahuan pada ibu hamil tentang anemia mempengaruhi konsumsi suplemen zat besi Puskesmas Sengkol. Stolzfus \& Dreyfuss (2012) menyatakan bahwa dalam banyak populasi, populasi [32]. Jumlah zat besi yang diserap dari makanan tidak mencukupi untuk memenuhi persyaratan banyak individu khususnya selama masa bayi dan kehamilan saat fisiologis kebutuhan besi adalah yang tertinggi. Penyerapan zat besi telah diamati dari suplemen zat besi oral dengan rata-rata sekitar $25 \%$ (Goodman \& Gilman, 1970) [33]. Menurut Galloway \& McGuire (1994) [34], Zat besi adalah nutrisi penting yang diperlukan untuk sintesis hemoglobin selain kesejahteraan normal yang permintaannya meningkat pesat selama kehamilan dan banyak kali tidak mendapatkan cukup suplai melalui diet biasa. Ini bisa diperparah dengan hilangnya nafsu makan selama kehamilan.

Ibu hamil dengan pengetahuan rendah mempunyai peluang 1,42 lebih tinggi untuk tidak patuh minum tablet besi dibandingkan ibu hamil yang berpengetahuan tinggi (Subarda, 2011) [35].

Menurut teori Lawrence Green dalam (Notoatmodjo, 2007), pengetahuan seseorang tentang kesehatan merupakan salah satu faktor presdidposisi yang mempengaruhi perilaku seseorang, jadi jika ibu hamil tidak mendapatkan informasi atau penyuluhan tentang anemia maka dapat berpengaruh dalam bagaimana ibu hamil tersebut menghindarkan dirinya dari anemia. Pengetahuan merupakan faktor yang penting untuk terbentuknya perilaku seseorang, karena dari pengalaman dan penelitian terbukti bahwa perilaku yang didasari pengetahuan akan lebih langgeng dari perilaku yang tidak didasari oleh 
pengetahuan. Dengan meningkatnya pengetahuan ibu hamil tentang anemia diharapkan akan terjadi perubahan perilaku ke arah yang mendukung kesehatan (Notoatmodjo, 2007) [36]. Dari penelitian ini menunjukkan semakin tinggi pengetahuan ibu hamil tentang anemia terdapat hubungan yang signifikan dengan kepatuhan mengonsumsi tablet besi.

\section{KESIMPULAN}

Dari penelitian ini menunjukkan ada Hubungan antara tingkat pengetahuan tentang anemia dengan kepatuhan ibu hamil meminum tablet zat besi di puskesmas sengkol nilai $\mathrm{p}=$ $0,009(\mathrm{p}<0,05)$ di mana semakin baik pengetahuan ibuhamil tentang anemia defisiensi besi maka semakin patuh ibu hamil minum tablet besi.

Saran dari penelitian ini adalah:

1. Perlunya tindakan penyuluhan dari petugas kesehatan kepada ibu hamil tentan anemia ibu hamil, akibat anemia ibu hamil, pencegahan anemia ibu hamil, dan pentingnya tablet besi bagi ibu hamil.

2. Bagi ibu hamil untuk lebih meningkatkan kepatuhan dalam mengkonsumsi tablet besi sebagai salah satu penanggunangan anemia ibu hamil selama kehamilan.

3. Bagi peneliti lain juga diharapkan dapat meneliti faktor-faktor lain yang berhubungan dengan kepatuhan mengkonsumsi tablet besi selain

\section{DAFTAR PUSTAKA}

[1] WHO. The global prevalence of anaemia in 2011. 2015.

[2] Ks Khan, Wojdyla D, Say L, Gu“lmezoglu AM, Van Look PF. WHO analysis of causes of maternal death: a systematic review. The Lancet. 2006; 367(9516):1066-74.

[3] Karaoglu L, Pehlivan E, Egri M, Deprem C, Gunes G, Genc MF, et al. The prevalence of nutritional anemia in pregnancy in an East Anatolian Province, Turkey. BMC Public Health. 2010; 10(1):1.
[4] Kefiyalew F, Zemene E, Asres Y, Gedefaw L. Anemia among pregnant women in southeast ethiopia: prevalence, severity and associated risk factors. BMC Research Notes. 2014; 7(1):1.

[5] Bothwell TH. Iron requirements in pregnancy and strategies to meet them. Am J Clin Nutr. 2000;72:257S-64S.

[6] Cantor AG, Bougatsos C, Dana T, Blazina I, McDonagh M. Routine iron supplementation and screening for iron deficiency anemia in pregnancy: a systematic review for the U.S. Preventive Services Task Force. Ann Intern Med. 2015;162:566-76.

[7] Milman N. Iron and pregnancy-a delicate balance. Ann Hematol. 2006;85:559-65.

[8] Pena-Rosas JP, Viteri FE. Effect and safety of preventive oral iron+folic acid supplementation for women during pregnancy. Cochrane Library; 2009.

[9] Guidelines for control of Iron Deficiency Anaemia: National Iron plus Initiative; 2013. 8.

[10] [RISKESDAS] Riset Kesehatan Dasar. (2017). Jakarta: Badan Penelitian dan Pengembangan Kesehatan Kementrian Kesehatan RI.

[11] RISKESDAS] Riset Kesehatan Dasar. (2013). Jakarta: Badan Penelitian dan Pengembangan Kesehatan Kementrian Kesehatan RI.

[12] RISKESDAS] Riset Kesehatan Dasar. (2018). Jakarta: Badan Penelitian dan Pengembangan Kesehatan Kementrian Kesehatan RI.

[13] Dikes Kabupaten Lombok Tengah. Pemantauan Wilayah Setempat Kesehatan Ibu dan Anak Tahun 2017. Dinas Kesehatan Kabupaten Lombok Tengah, 2017.

[14] Erwin, R. R., Machmud, R. \& Utama, B. I. Artikel Penelitian Hubungan Pengetahuan dan Sikap Ibu Hamil dengan Kepatuhan dalam Mengkonsumsi Tablet Besi di Wilayah Kerja Puskesmas Seberang Padang Tahun 2013. J. Kesehat. Andalas 6, 596601 (2017)

[15] Galloway R, McGuire J. Determinants of compliance with iron supplementation: Supplies, side effects, or psychology? Social Science \& Medicine 1994; 39:38190. 
[16] Zakia m. Ibrahim, seham abd el-hamid, Hend Mikhail, and Maged S. Khattab, 2011, Assessment of Adherence to Iron and Folic Acid Supplementation and Prevalence of Anemia in Pregnant Women, Med. J. Cairo Univ., Vol. 79, No. 2, June 115-121, 2011

[17] RISKESDAS] Riset Kesehatan Dasar. (2016). Jakarta: Badan Penelitian dan Pengembangan Kesehatan Kementrian Kesehatan RI.

[18] Galloway R, McGuire J. Determinants of compliance with iron supplementation: Supplies, side effects, or psychology? Social Science \& Medicine 1994; 39:38190.

[19] Allen LH. Anaemia and iron deficiency. effects on pregnancy outcome. Am J Clin Nutr 2000;71(suppl):1288S-94S. 6. Scholl OT, Johnson WG. Folic acid. influence on the outcome of pregnancy. Am J Clin Nutr 2000; 71(suppl):1295S-303S

[20] Iron deficiency anaemia assessment, prevention and control. Available from URL http:// www. w h o .int/vmnis/indica tor s / haemoglobin.pdf (Accessed on 10-092012).

[21] Dinas Kesehatan Nusa Tenggara Barat (2013), Profil Kesehatan Nusa Tenggara Barat: Mataram: Dinas Kesehatan Nusa Tenggara Barat.

[22] Nursalam. 2013. Metodologi Penelitian Ilmu Keperawatan: Pendekatan Praktis : Jakarta : Salemba

[23] Dahlan, Sopiyudin M. 2013. Besar Sampel dan Cara Pengambilan Sampel. Jakarta: Salemba Medika

[24] Notoadmojo, (2014), Ilmu Perilaku Kesehatan, Edisi pertama, Rineka Cipta, Jakarta, Indonesia

[25] Maskey M, Jha N, Poudel SI, Yadav D. Anemia in pregnancy and its associated factors: A study from Eastern Nepal. Nepal Journal of Epidemiology. 2014;4(4):38692.

[26] Abdelnefez AM, EI-Soadaa SS. Prevalence and risk factors of anemia among a sample of pregnant females attending primary health care .Pak J Nutr. 2012;11:1113-20.

[27] Dorairajan G, Palanivel C, Sakthi D. Influence of awareness and attitude about anemia and iron

[28] Nivedita K, Shanthini FN. Knowledge, attitude and practices of pregnant women regarding anemia, iron rich diet and iron supplements and its impact on their hemoglobin levels. Int J Reprod Contracept Obstet Gynecol. 2016;5:425-31

[29] World Health Organization (WHO). 2012. Guideline: Daily iron and folic acid supplementation in pregnant women. Geneva, World Health Organization.

[30] Gebre, A. 2015. Assessment of Factors Associated with Adherence to Iron-Folic Acid Supplementation Among Urban and Rural Pregnant Women in North Western Zone of Tigray, Ethiopia: Comparative Study, International Journal of Nutrition and Food Sciences. 4 (2)

[31] Saxena, R. 2014. Bedside obstetrics \& gynecology. 2nded. New Delhi, India: Jaypee Brothers Medical Publishers. p 585.

[32] Stoltzfus, R.J. \& Dreyfuss, M.L. 2012. Guidelines for the use of iron supplements to prevent and treat iron deficiency. Washington, United States: ILSI Press. Pp. 4-18

[33] Goodman, L.S. \& Gilman, A. (1970). The pharmacological basis of therapeutics. 4th ed. New York: Macmillan Co.

[34] Galloway, R. \& McGuire, J. 1994. Determinants of compliance with iron supplementation: Supplies side effects, or psychology? Social Science \& Medicine 39: 381-390.

[35] Subarda, Hakimi.M, Helmyat.S (2011) Pelayanan antenatal care dalam pengelolaan anemia berhubungan dengan kepatuhan ibu hamil minum tablet besi. Jurnal Gizi Klinik Indonesia. 8(1), 7-13

[36] Notoatmodjo, Soekidjo, 2007, Promosi Kesehatan dan Ilmu Perilaku, Rineka Cipta, Jakarta, hal. 133, 139, 140-143. 